\title{
Comprehensive Evaluation of Biomass Energy Technologies in China
}

\author{
Qing Yang ${ }^{1,2}$, Fei $\operatorname{Han}^{1}$, Xudong $\mathrm{Wu}^{1,3}$, Deyuan Wang ${ }^{1}$, Xianhua Wang ${ }^{1}$, Haiping Yang ${ }^{1, *}$, \\ Shihong Zhang ${ }^{1}$ and Hanping Chen ${ }^{1}$
}

\author{
${ }^{1}$ State Key Laboratory of Coal Combustion, Huazhong University of Science and Technology, Wuhan \\ 430074, P.R. China \\ ${ }^{2}$ Department of New Energy Science and Engineering, School of Energy and Power Engineering, Huazhong \\ University of Science and Technology, Wuhan 430074, P.R. China \\ ${ }^{3}$ College of Engineering, Peking University, Beijing 100871, P.R. China
}

\begin{abstract}
Based on a comprehensive review of the different biomass energy technologies in China, a hybrid evaluation model founding on Analytic Hierarchy Process (AHP) is proposed to offer a comprehensive evaluation of a variety of biomass energy technologies in China. In this model, three evaluation criteria, including the applicability of technology, economic viability and environment-friendly, are defined and nine indicators, including resources supply, equipment and technology, energy efficiency, energy grade, production cost, economic benefit, ecological impact, environmental pollution and social benefit, are devised. Priorities are established in this study based on pairwise comparisons of the elements. In addition, the model has been validated by various utilization technologies reported in literatures. Results show that environmental pollution, social benefit, ecological impact and resources supply greatly impact on the application of biomass technologies, followed by economic benefit. Besides, it is demonstrated that integrated technologies of biomass energy, which is closely related with residential daily life and compatible with local ecological environment, possess evident superiority. Furthermore, the outcome can be supportive for guiding future development of biomass energy in China.
\end{abstract}

Keywords: Biomass energy technologies, analytic hierarchy process, comprehensive evaluation, development, China.

\section{INTRODUCTION}

Solar radiation can be transformed into chemical energy stored in organisms via photosynthesis of plants, which is the source of bio-energy. Through photosynthesis, plants on Earth can synthesize about 1400 1800Gt dried biomass every year, the energy contained in which is equal to 10 times of the world total power consumption each year [1]. Compared with conventional fossil fuels, biomass resources have some inherent advantages on characteristic for providing energy, as referring to a low sulfur content, small ash proportion, neutral $\mathrm{CO}_{2}$ emission, and widely distribution [2, 3]. Therefore, the exploitation and utilization of biomass resources has aroused extensive attention all over the world [4]. Nevertheless, despite these advantages endowed with biomass resources, drawbacks are also quite clear, such as low energy density, high cost for transportation, and low ash fusion point.

At present, there exist a variety of biomass energy technologies, and can be classified as thermo

*Address correspondence to this author at the State Key Laboratory of Coal Combustion, Huazhong University of Science and Technology, Wuhan 430074, P.R. China; Tel: +86 2787542417 ; Fax: +86 2787540724 ;

E-mail: yhping2002@163.com conversion, chemical conversion and biochemical conversion technologies, with a large range of capacity [5]. Vast studies are undertaken to present an assessment for these technologies [6-9]. Saft (2007) [10] investigated a full scale pyrolysis/gasification plant in Netherland and quantified its environmental performance by means of an impact assessment method. Koroneos et al. (2008) [11], Luterbacher et al. (2009) [12], and Puy et al. (2010) [13] conducted several assessments for biomass gasification technologies in a life cycle perspective, the results of which demonstrated that gasification was accompanied with environmental pollution, due to resources consumption and indirect emissions from upstream and downstream processes. Yang et al. (2009) [14] used the cumulative exergetic method based on the integrated process including agricultural crop production, corn transportation, industrial conversion and waste treatment as a whole to identify the renewability of total corn-ethanol production in the national level of China the results showed that 3.84 times more energy was consumed in corn-ethanol processes than was produced. Ou et al. (2009) [15] used the Tsinghua-CA3EM (China Automotive Energy, Environment and Economy Model) model, which was based on China's national conditions with the 
integration of the widely known transportation energy micro-level computing GREET model, and presented energy consumption of China's current six biofuel pathways. Maraver et al. (2009) [16] studied the economic feasibility and the corresponding environmental impacts for a trigeneration system using the exergy method, which showed that biomass trigeneration schemes in general had unique advantages for reducing environmental impacts in power generation. Sebastián et al. (2011) [17] carried out an study to determine the reduction of greenhouse gas emissions in China that could actually be attained when the co-firing of different biomass resources was compared to coal-fired electricity generation in the same power plant in a cradle-to-grave manner. While Basu et al. (2011) [18] performed an technicaleconomic analysis for several co-firing cases and confirmed the economic viability of biomass co-firing.

As shown from the above studies, different technologies tend to be with varied performances. In addition, the biomass distribution, energy efficiency, economy and environmental impact are quite different for varied biomass energy plants in different areas. As a result, it is of great concern of choosing the optimal utilization model fitting to the local development, which not only involves the state of the art of a certain technology, but also relates to the context of energy consumption in the whole region. Therefore, the comprehensive evaluation to various biomass utilization technologies is particularly urgent, especially in China, which feeds more people with fewer land. In this context, based on a review of different technologies of biomass energy, an evaluation model based on Analytic Hierarchy Process (AHP) method is proposed to assess different technologies of biomass energy in China, which is of significant importance to government planning on future development of biomass energy.

\section{EVALUATION MODEL BASED ON ANALYTIC HIERARCHY PROCESS}

\subsection{Evaluation Method}

The analytic hierarchy process (AHP) was first developed by Thomas L. Saaty in the 1970s [19], and then has been extensively studied and refined. It is a structured technique for organizing and analyzing complex decisions, based on mathematics and psychology, and has particular application in group decision making [20], in fields such as government, business, industry, healthcare, and education [2].
The evaluation process based on AHP method consists of the following steps:

First, a model of hierarchical structure should be established. According to the property of each impact factor of a problem, different factors should be divided into several hierarchies. The top hierarchy is the decision goal and always includes one factor, and then some criteria hierarchies or indicator hierarchies should be followed. More details of the evaluation indicators are discussed in the next section.

Second, priorities are established among the elements of the hierarchy by making a series of judgments based on pairwise comparisons of the elements. For example, according the priority of $A$ and $B$, scores are given from 1 to 9 . The higher the score is, the more important $A$ is than $B$.

Third, these judgments are synthesized to yield a set of overall priorities for the hierarchy. And the consistency of judgments has been checked.

Finally, a final decision has been made based on the results of the processes above.

\subsection{Evaluation Model}

In this study, an evaluation model has been established based on AHP method to comprehensively assess different biomass energy technologies in China.

First, according to the property of biomass energy, resource, environment, economy, ecology and social development, an evaluation model based on AHP method is established (as shown in Figure 1). The decision goal is to select an ideal biomass conversion technology (IBCT) for an area. The criteria contain applicability of technology (AT), economic viability (EV) and environment-friendly (EF). Applicability of technology determines the enforceability of utilization technology routes and is the basis of project implementation; economic viability represents the sustainability of utilization technology projects and is the guarantee of project implementation; environmentfriendly standardizes the possibility of sustainable development in the utilizing technology processes and is the precondition of project implementation. Based on technology, economy and environment, evaluation is propitious to achieve the comprehensiveness and scientificness of comparison among utilization technology projects. Due to the unique features of biomass energy and the claim for establishing systematic evaluation criteria, nine indicators are 


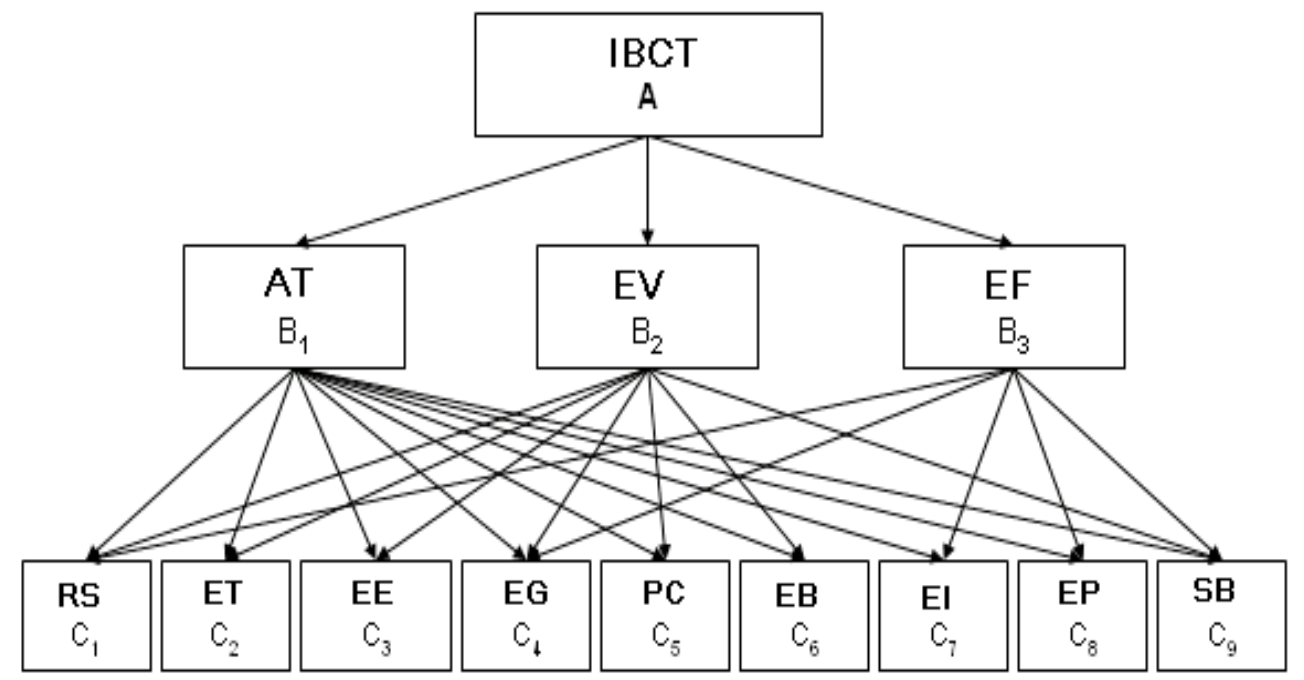

Figure 1: The evaluation model based on Analytic Hierarchy process (AHP).

Abbreviations: IBCT: Ideal Biomass Conversion Technology; AT: Applicability of technology; EV: Economic viability; EF: Environment-friendly; RS: Resources supply; ET: Equipment and technology; EE: Energy efficiency; EG: Energy grade; PC: Production cost; EB: Economic benefits; El: Ecological impact; EP: Environmental pollution; SB: Social benefit.

devised for the evaluation model, including resources supply (RS); equipment and technology (ET); energy efficiency (EE); energy grade (EG); production cost $(P C)$; economic benefit (EB); ecological impact (EI); environmental pollution (EP); social benefit (SB). These nine indicators are detailed clarified as follows:

\section{(1) Resources supply (RS)}

With a view to the widely distribution, seasonality and low energy density features endowed with biomass resources, this indicator is devised, which is generated by demand relations between theoretic radius $\left(R_{L}\right)$ and market radius $\left(R_{S}\right)$ rather than the absolute quantity of biomass resources consumption in varied biomass technologies. The equation is defined as:

$S=f\left(R_{L} \vee R_{S}\right)$

where $S$ is the evaluation indicator for resources supply. $R_{L}$ is the radius determined by the requisite resources in biomass energy systems. $R_{S}$ is the radius regulated by market conditions in actual marketing. $R_{L} \vee R_{S}$ represents the numerical comparison between them, and $f$ stands for the generating function. If $R_{L} \gg R_{S}$, it indicates that resources supply is insufficient, which will lead to a low value of corresponding indicator. On the contrary, if $R_{L} \ll<R_{S}$, it implies an abundant resources supply and a relatively high value of the evaluation indicator. While in the middle state, the indicator value needs to be adjusted accordingly.
(2) Equipment and technology (ET)

Technology maturity $\left(T_{M}\right)$, along with the standardization and localization of manufacturing technology $\left(T_{S}\right)$ as well as associated technical services $\left(T_{F}\right)$, paves the way for the application of biomass energy and directly determines the indicator value. The indicator is defined as:

$T=f\left(k, T_{M}, T_{S}, T_{F}\right)$

where $T$ is the indicator for the equipment and technology. $k$ represents the accommodation coefficient among the various parameters. The developmental level of equipment and technology is directly related to the expansion of relevant technology application, which is neglected by most scholars in previous studies.

\section{(3) Energy efficiency (EE)}

This indicator is very crucial to evaluate the energy conversion efficiency, which is defined as:

$\eta=M_{1} / M_{0}$

where $\eta$ represents the energy efficiency. $M_{0}$ indicates the total quantity of biomass resources, and $M_{1}$ is the quantity of biomass resources that are transformed into final products.

(4) Energy grade (EG)

Due to the diversity of resources grade and varied human demands for different kinds of energy, energy in 
various forms tends to be with varied performances. Classified by the final form from biomass conversion, the ultimate energy can be divided into liquid fuel $(L)$, gas $(G)$, heating $(W)$, and electricity $(E)$. According to the current status of energy demand in China, these four energy forms are sorted as follows:

$L>E>G>W$

Besides, in the course of analysis and quantification for energy grade, the transformation quality needs to be taken into account.

\section{(5) Production cost (PC)}

Production cost is an important parameter for the measurement of economic feasibility, the magnitude of which may greatly impact on the investor and investment scale. Production cost mainly consists of construction cost $\left(C_{1}\right)$, cost of raw materials $\left(C_{2}\right)$ and operation $\operatorname{cost}\left(\mathrm{C}_{3}\right)$, which is clarified as:

$C=C_{1}+C_{2}+C_{3}$

With regard to the various technologies of biomass energy, the construction cost is mainly determined by the utilization modes and the scale that differ greatly in varied technologies. Comparatively speaking, cost of raw materials depends largely on resources supply while operation cost remains steady.

\section{(6) Economic benefit (EB)}

The project profitability can be directly characterized here. Corresponding calculation methods mainly comprise the dynamic investment payback method, the net present value method, internal rate of return method, etc. In this study, net present value (NPV) is adopted as the tool for measurement due to its distinct intuitive feature for measurement, as is shown below [21]:

$$
N P V=\sum_{t=1}^{n}\left(C I_{t}-C O_{t}\right)\left(1+i_{o}\right)^{-t}
$$

where $n$ is the fixed number of years taken into account. $i_{o}$ represents benchmark yield ratio; $C I_{t}$ is the annual profit and $\mathrm{CO}_{t}$ stands for annual budget. In a life cycle perspective, the project is profitable in the condition when the net present value $N P V\left(i_{0}\right) \geq 0$. In addition, preferential policies and related subsidies also make up an indispensable part of the project profitability.
(7) Ecological impact (El)

The main purpose of setting up the ecological impact indicator is for a better understanding of the regional ecological characteristics and function, as well as identifying the ecological impact of the projects and sensitivity of the ecosystem. Therefore corresponding measures could be taken to mitigate the ecological damage, thus attaining sustainable utilization of natural resources [22]. Previously few scholars employ this evaluation indicator, the reason of which may be attributed to the hysteretic concept and the inconvenience of quantification for ecological impact. For the closely related relationship between biomass energy and regional ecology, it is necessary and of great significance to evaluate the ecological impact of biomass energy technologies. The objective is to reach a balance between the maximization of biomass energy application benefits and minimization of ecological damage. It is a complex and brand new task for the quantification of ecological impact. In this paper we try to achieve this target with compensation for the ecological impact, as shown below:

$Z=\sum_{t=1}^{n} C Z_{t}\left(1+i_{o}\right)^{-t}$

where $Z$ stands for the loss of economic profit due to compensation for ecological impact. $C Z_{t}$ represents annual budget on ecological recovery. When $C Z_{t}>0$, it implies the application of technologies is beneficial for the ecology and may hence gain relevant profits. On the contrary, when $C Z_{t}<0$, this means extra money needs to be paid to make up for the ecological damage.

(8) Environmental pollution (EP)

Renewability and environmental friendly, lead to increasing concern on technologies of biomass energy. However, it is impossible to achieve non-pollution and zero- $\mathrm{CO}_{2}$ emission in the whole process. Quantification of environmental pollution could comprehensively assess the technology availability, and at the same time it suggests a path for solution to environmental pollution. In this study the method of damage estimation is employed to determine the environmental pollution by using the following formula:

$P=\sum_{t=1}^{n}\left(C P_{t}+C S_{t}\right)\left(1+i_{o}\right)^{-t}$ 
where $P$ stands for environmental pollution. $C P_{t}$ is the annual budget on bio-safety disposal of pollutants. $C S_{t}$ represents the annual payment on environmental pollution.

\section{(9) Social benefit (SB)}

Unlike traditional fossil energy, exploitation and utilization of biomass energy largely impact on the regional production mode and lifestyle. Hence the social benefit will have a great influence on the project vitality. Social benefit, an open and flexible indicator, is manifested in the improvement of living environment, enhancement of living quality, etc. In this study the social net present value (SNPV) is employed as the indicator for social benefit, which is determined by [23]:

$$
S N P V=\sum_{t=1}^{n}\left(S C I_{t}-S C O_{t}\right)(1+A R I)^{-t}
$$

where ARI stands for social benchmark yield ratio. $S C I_{t}$ is the annual social income. $S C O_{t}$ represents annual social expenditure.
Based on the above analysis, with full consideration of the characteristics rooted in biomass energy technologies, pairwise comparisons of the elements are conducted to investigate the correlations among various indicators (as shown in Tables 1-4). With the consistency of judgment being checked, the proportion of each evaluation indicator could be obtained [19], as illustrated in Figure 2. It can be seen from the result that environmental pollution, social income, ecological impact, and resources supply occupy high proportions among the evaluation indicators, followed by economic benefit. The proportional distribution is consistent with the initial intention of biomass energy utilization and is therefore proven to be reasonable. The identification of the proportional distribution may lay a solid foundation for the subsequent comparisons on technologies of biomass energy.

\section{RESULTS AND DISCUSSION}

On the basis of the analysis for state of the art of existing biomass technologies [24-34], the indicators are calculated for various biomass energy technologies, as shown in Table 1.

Table 1: Comparisions of Ideal Biomass Conversion Technology (IBCT) and Different Criterias

\begin{tabular}{|c|c|c|c|}
\hline Item & AT & EV & EF \\
\hline \hline A & B1 & B2 & B3 \\
\hline B1 & 1 & $1 / 3$ & $1 / 5$ \\
\hline B2 & 3 & 1 & $1 / 5$ \\
\hline B3 & 5 & 5 & 1 \\
\hline
\end{tabular}

Consistency ratio of judgement matrix: 0.0171; Weight: 1.0000 .

Table 2: Comparisions of Applicability of Technology (AT) and Different Indicators

\begin{tabular}{|c|c|c|c|c|c|c|c|c|c|}
\hline AT & RS & ET & EE & EG & PC & EB & EI & EP & SB \\
\hline \hline B1 & C1 & C2 & C3 & C4 & C5 & C6 & C7 & C8 & C9 \\
\hline C1 & 1 & 3 & 2 & 2 & $1 / 2$ & $1 / 3$ & $1 / 5$ & $1 / 7$ & $1 / 3$ \\
\hline C2 & $1 / 3$ & 1 & 1 & $1 / 3$ & $1 / 2$ & $1 / 3$ & $1 / 5$ & $1 / 7$ & $1 / 3$ \\
\hline C3 & $1 / 2$ & 1 & 1 & 3 & $1 / 2$ & $1 / 3$ & $1 / 5$ & $1 / 7$ & $1 / 3$ \\
\hline C4 & $1 / 2$ & 3 & $1 / 3$ & 1 & $1 / 2$ & $1 / 3$ & $1 / 5$ & $1 / 7$ & $1 / 3$ \\
\hline C5 & 2 & 2 & 2 & 2 & 1 & $1 / 3$ & $1 / 7$ & $1 / 7$ & $1 / 5$ \\
\hline C6 & 3 & 3 & 3 & 3 & 3 & 1 & $1 / 5$ & $1 / 5$ & $1 / 3$ \\
\hline C7 & 5 & 5 & 5 & 5 & 7 & 5 & 1 & $1 / 3$ \\
\hline C8 & 7 & 7 & 7 & 7 & 7 & 5 & 3 & 1 \\
\hline C9 & 3 & 3 & 3 & 3 & 5 & 3 & 1 & $1 / 3$ \\
\hline
\end{tabular}

Consistency ratio of judgement matrix: 0.0107; Weight: 0.2062 . 
Table 3: Comparisions of Economic Viability (EV) and Different Indicators

\begin{tabular}{|c|c|c|c|c|c|c|c|}
\hline EV & RS & ET & EE & EG & PC & EB \\
\hline \hline B2 & C1 & C2 & C3 & C4 & C5 & C6 & C9 \\
\hline C1 & 1 & 3 & 3 & 2 & $1 / 5$ & $1 / 7$ & $1 / 3$ \\
\hline C2 & $1 / 3$ & 1 & 2 & 2 & $1 / 5$ & $1 / 3$ \\
\hline C3 & $1 / 3$ & $1 / 2$ & 1 & 1 & $1 / 5$ & $1 / 7$ & $1 / 3$ \\
\hline C4 & $1 / 2$ & $1 / 2$ & 1 & 1 & $1 / 5$ & $1 / 3$ \\
\hline C5 & 5 & 5 & 5 & 5 & 5 & $1 / 5$ & 1 \\
\hline C6 & 7 & 7 & 7 & 3 & 3 & $1 / 3$ \\
\hline C9 & 3 & 3 & 3 & 3 & $1 / 3$ \\
\hline
\end{tabular}

Consistency ratio of judgement matrix: 0.0088 ; Weight: 0.2693 .

Table 4: Comparisions of Environment-Friendly (EF) and Different Indicators

\begin{tabular}{|c|c|c|c|c|c|}
\hline EF & RS & EG & EI & EP & SB \\
\hline B1 & C1 & $\mathrm{C} 4$ & $\mathrm{C} 7$ & C8 & $\mathrm{C9}$ \\
\hline C4 & $1 / 5$ & 1 & $1 / 5$ & $1 / 7$ & $1 / 5$ \\
\hline $\mathrm{C} 7$ & 3 & 5 & 1 & $1 / 3$ & 2 \\
\hline $\mathrm{Cg}$ & 2 & 5 & $1 / 2$ & 1 & 1 \\
\hline
\end{tabular}

Consistency ratio of judgement matrix: 0.0086; Weight: 0.5245 .

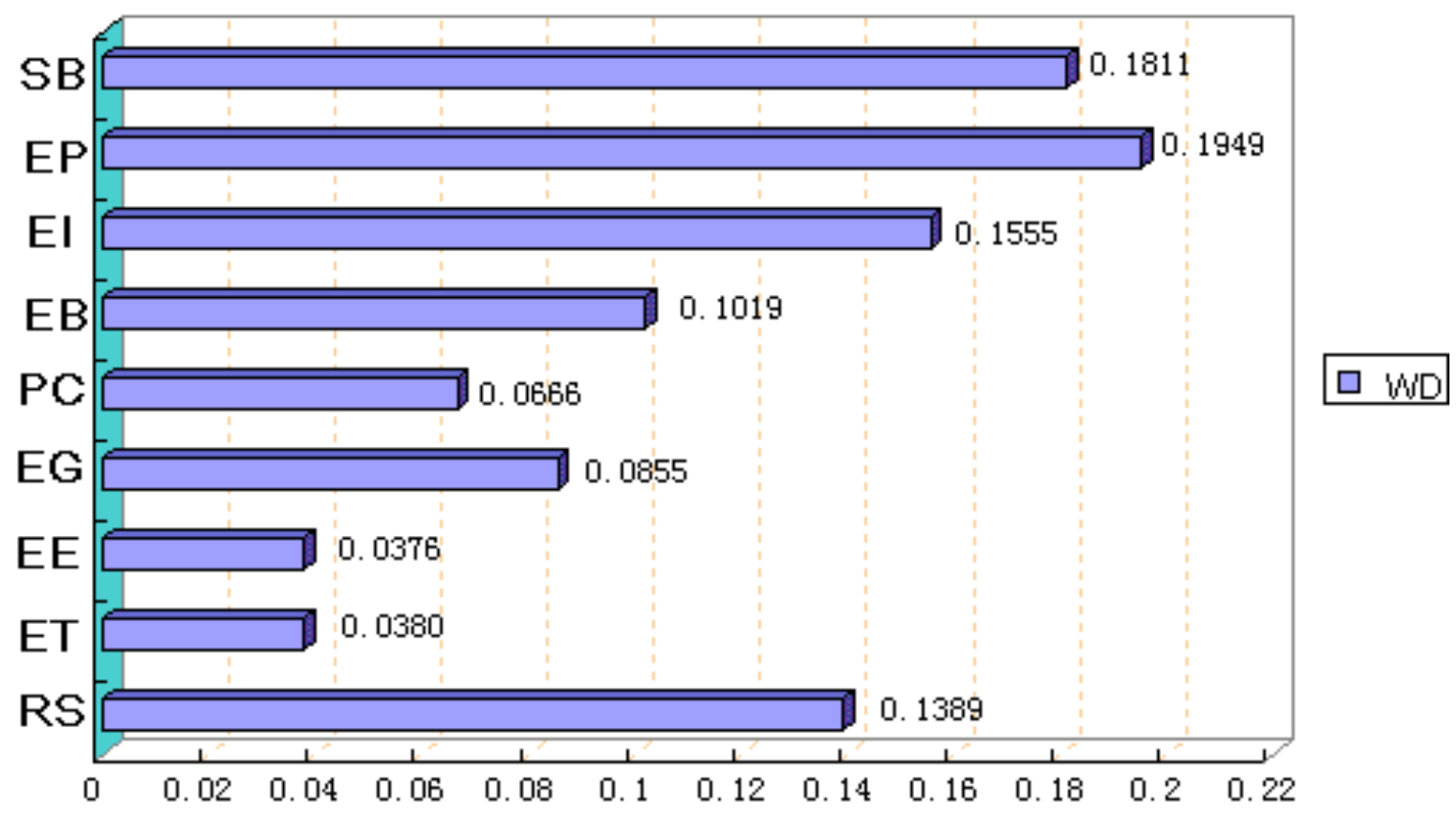

Figure 2: Proportional distribution of evaluation indicators for biomass energy technologies. 
Table 5: Scores of Systematic Indicators for Typical Biomass Energy Systems

\begin{tabular}{|c|c|c|c|c|c|c|c|c|c|c|c|c|c|c|}
\hline Indicator & Weight & BDC & СВC & WSI & BF & BG & B-IGCC & SG & FE & Bio-diesel & Bio- oil & HM & LSLM & OWM \\
\hline RS & 0.1389 & 65 & 70 & 80 & 90 & 60 & 50 & 85 & 55 & 40 & 65 & 90 & 90 & 90 \\
\hline ET & 0.038 & 70 & 75 & 60 & 65 & 45 & 30 & 80 & 80 & 70 & 60 & 90 & 80 & 80 \\
\hline EE & 0.0376 & 60 & 55 & 70 & 80 & 75 & 80 & 60 & 90 & 80 & 70 & 95 & 90 & 70 \\
\hline EG & 0.0855 & 70 & 70 & 70 & 70 & 80 & 85 & 75 & 90 & 90 & 85 & 85 & 85 & 80 \\
\hline PC & 0.0666 & 60 & 70 & 75 & 90 & 50 & 30 & 60 & 80 & 75 & 60 & 90 & 80 & 70 \\
\hline EB & 0.1019 & 60 & 60 & 70 & 80 & 40 & 20 & 50 & 85 & 80 & 65 & 70 & 85 & 75 \\
\hline EI & 0.1555 & 65 & 65 & 70 & 80 & 60 & 60 & 65 & 55 & 50 & 60 & 80 & 85 & 90 \\
\hline EP & 0.1949 & 70 & 70 & 50 & 80 & 45 & 60 & 50 & 90 & 85 & 70 & 95 & 95 & 95 \\
\hline SB & 0.1811 & 60 & 70 & 50 & 80 & 40 & 35 & 70 & 85 & 70 & 60 & 95 & 85 & 90 \\
\hline
\end{tabular}

Abbreviations: BDC: Biomass direct combustion; CBC: Coal-biomass combustion; WSI: Waste and sludge incineration; BF: Briquettes fuel; BG: Biomass gasification; B-IGCC: Biomass integrated gasification combined cycle; SG: Straw gasification; FE: Fuel ethanol; HM: Household methane; LSLM: Large-Scale livestock methane; OWM: Organic wastewater methane.

Afterwards, synthesis scores could be obtained for various energy systems via a weighted calculation as the following formula:

$$
S_{X_{j}}=\sum C_{i} \times X_{j i}
$$

Where $X_{j}$ denotes the biomass conversion technology, such as BDC, WSI and so on, $S_{X_{j}}$ is the final score of technology $X_{j}, C_{i}$ is the evaluation indicators and $X_{j i}$ is the score of $X_{j}$.

The results are shown in Figure 3 . It is illustrated in the figure that household methane system, large-scale livestock methane system and organic wastewater methane system are accompanied with relative higher scores, the reason of which may be ascribed to the abundant resources supply, mature equipment and technology, as well as an favorable integration with pollution disposal and ecological construction, thus realizing the coordinated development of resources, environment, ecology and technology [31, 34]. Besides, the briquettes fuel and fuel ethanol turn out with a good appraisal as well. Briquettes fuel is consistent with the energy consumption habits in rural areas and is therefore easy to be accepted. The convenience for acceptance, along with the low investment, abundant resources supply, and preliminary commercialization of equipment and technology, foresees a bright future for briquettes fuel $[30,31]$. As for fuel ethanol, it mainly benefits from the relatively higher energy grade of liquid fuel. Moreover, raw materials for fuel methanol system have been extended from specific crop stalks to general cellulose stalks and its technical application is rapidly expanded by leading enterprises, basically possessing the preconditions for industrialization. However, bio-diesel and bio-oil technologies, with similar initial goal of producing liquid fuel, fall behind. This is because that bio-diesel is now undergoing the small-scale demonstration period, technological applications of which are not mature enough. The immaturity, combined with the special requirements for energy supply and underlying ecological damage, lead to a lower score for bio-diesel $[32,33]$. With regard to bio-oil, though owning superiority in resources supply, the immature technology, especially in the bio-oil quality, manifests that the energy system is still far from commercial application. On the average, biomass liquefaction technologies own slight superiority over biomass combustion power generation technologies. On the one hand, this is due to the higher energy grade of liquid fuel and the "recycling" potential. On the other hand, intensive sensitivity to resource prices, higher investment and operation costs stand in the way for expansion of biomass combustion power generation technologies. However, compared to biomass direct combustion power generation, coal-biomass power generation is more preferable, which primarily benefits from the flexible resources supply, lower risk of price soar in resources and a relatively lower investment cost. For waste and sludge incineration generation, the superiority is not evident, which is mainly restricted by the pressure from environment pollution. Though it is propelled by huge demands, new pollutants emitted in incineration result in an awkward situation. Research for a comprehensive disposal program is therefore of particular urgency.

As illustrated in Figure 3, score for gasification technology is relatively lower, deriving from the constraints of the technology itself, which is immature 


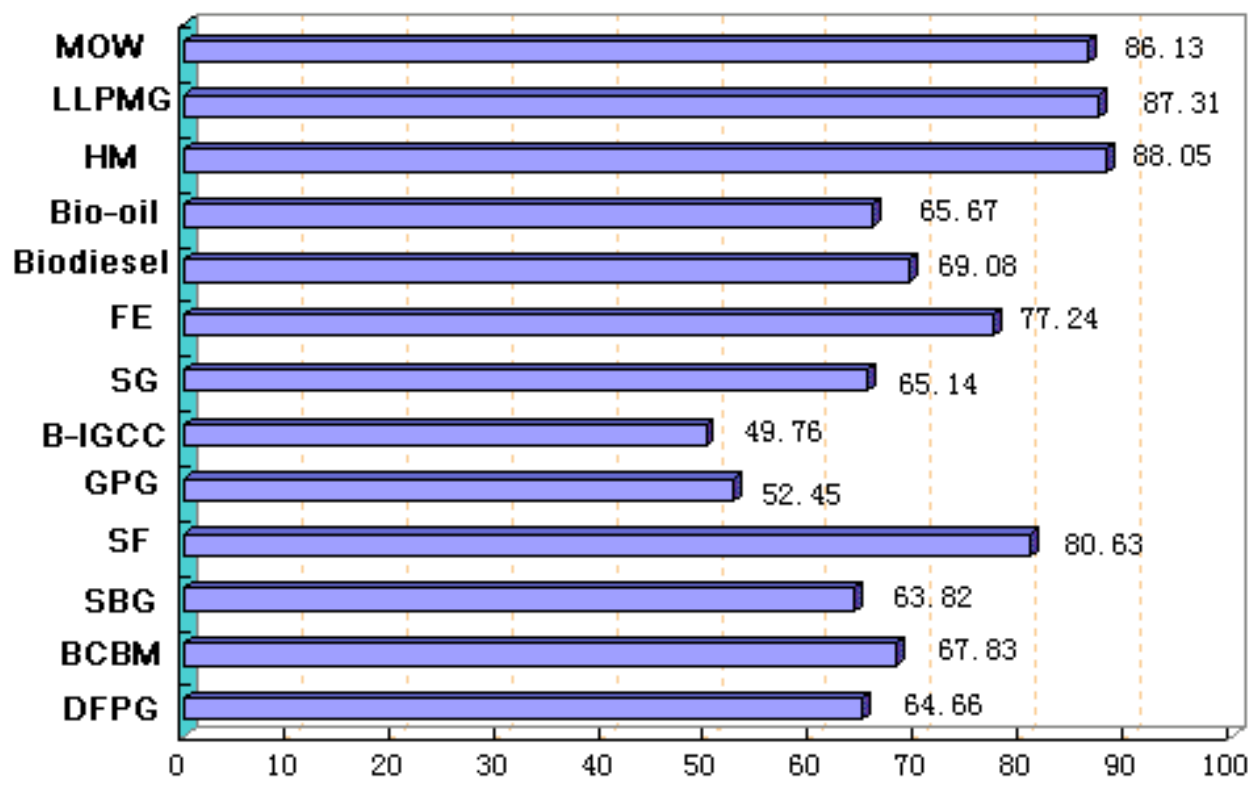

Figure 3: Comprehensive evaluation results for typical biomass energy systems.

and accompanied with high operation costs. Although the straw gasification technology is advantageous in supplying resources and enhancing energy quality in rural areas, its drawbacks embodied in large investment, low profit, unscientific operation and management modes, lead to a dilemma in the promotion of its application [29]. For the gasification power generation technology, though equipped with relatively high systematic efficiency and great potential for "recycling", negative factors including high investment and secondary pollution directly result in a gloomy prospect. Similarly, B-IGCC, serving as the future demonstration project, is still far from commercial application with more demanding requirements for technology and equipment.

\section{CONCLUSIONS}

This paper has presented a hybrid evaluation model to comprehensively assess various biomass energy technologies in China based on Analytic Hierarchy Process (AHP). The outcome could serve as guidelines for future development of biomass technologies.

Biomass energy differs from the traditional fossil energy in the distinct characteristics embodied in resources supply, raw materials features, correlations with environment, ecology and society, etc. As a result, the perspective on biomass energy exploitation shall not be rested solely on the level of technology application, but on a global context including resources supply, environment, ecology, economy and social impacts. In this way, the goal could be ultimately achieved for rational utilization of biomass resources for sustainable development.

Based on the hybrid evaluation model, three criteria and nine indicators are devised. The result shows that environmental pollution, social benefit, ecological impact and resources supply have a large impact on the application of biomass technologies, followed by economic benefit.

Comprehensive evaluation results demonstrate that integrated technologies of biomass energy, which is closely related with residential daily life and compatible with local ecological environment, obtain an obvious advantage. Therefore technologies on the basis of "moderate size", "comprehensive development", "recycling" and "step-by step realization" depict a bright picture for future biomass resources utilization in China.

\section{ACKNOWLEDGEMENTS}

This work is supported by the National Natural Science Foundation of China (Grant Nos. 51306067, 51376076) and the Natural Science Foundation of Hubei Province (Grant No. 2013CFB179). We also would like to thank Miss Heather Ramsay for her generous help and comments.

\section{REFERENCES}

[1] Wu CZ, Ma LL. Modern utilization technologies of biomass energy. Beijing: Chemical Industrial Publisher 2003. 
[2] Zhang Y, Zhou SP, Su F. Fuzzy mathematical method and its application. Beijing: China Coal Industry Publishing House, 1992.

[3] Chen GQ, Zhang B. Greenhouse gas emissions in China 2007: Inventory and input-output analysis. Energy Policy 2010; 38: 6180-93. http://dx.doi.org/10.1016/j.enpol.2010.06.004

[4] Murphy JD, Power N. A technical, economic, and environmental analysis of energy production from newspaper in Ireland. Waste Manag 2007; 27: 177-92. http://dx.doi.org/10.1016/j.wasman.2006.01.003

[5] Faaij APC. Bio-energy in Europe: changing technology choices. Energy Policy 2006; 34: 322-42. http://dx.doi.org/10.1016/j.enpol.2004.03.026

[6] Berglund $M$, Börjesson P. Assessment of energy performance in the life-cycle of biogas production. Biomass Bioenergy 2006; 30: 254-66. http://dx.doi.org/10.1016/j.biombioe.2005.11.011

[7] Robinson A, Rhodes J, Keith D. Assessment of potential carbon dioxide reductions due to biomass-coal cofiring in the United States. Environ Sci Technol 2003; 37: 5081-9. http://dx.doi.org/10.1021/es034367q

[8] Caputo AC, Palumbo M, Pelagagge PM, Scacchia F. Economics of biomass energy utilization in combustion and gasification plants: effects of logistic variables. Biomass Bioenergy 2005; 28: 35-51. http://dx.doi.org/10.1016/j.biombioe.2004.04.009

[9] Ju L, Chen B. Embodied energy and emergy evaluation of a typical biodiesel production chain in China. Ecol Model 2011; 222: 2385-92.

http://dx.doi.org/10.1016/j.ecolmodel.2010.07.021

[10] Saft RJ. Life cycle assessment of a pyrolysis/gasification plant for hazardous paint waste. Int J Life Cycle Ass 2007; 12: $230-8$.

http://dx.doi.org/10.1007/s11367-007-0332-6

[11] Koroneos C, Dompros A, Roumbas G. Hydrogen production via biomass gasification - A life cycle assessment approach. Chem Eng Process 2008; 47: 1267-74.

http://dx.doi.org/10.1016/j.cep.2007.04.003

[12] Luterbacher JS, Froling M,Vogel F, Maréchal F, Tester JW. Hydrothermal gasification of waste biomass: process design and life cycle asessment. Environ Sci Technol 2009; 43: 1578-83.

http://dx.doi.org/10.1021/es801532f

[13] Puy N, Rieradevall J, Bartroll J. Environmental assessment of post-consumer wood and forest residues gasification: The case study of Barcelona metropolitan area. Biomass Bioenergy 2010; 34: 1457-65.

http://dx.doi.org/10.1016/j.biombioe.2010.04.009

[14] Yang Q, Chen B, Ji X, He YF, Chen GQ. Exergetic evaluation of corn-ethanol production in China. Commun Nonlinear Sci Numer Simul 2009; 14: 2450-61. http://dx.doi.org/10.1016/j.cnsns.2007.08.011

[15] Ou X, Zhang X, Chang S, Guo Q. Energy consumption and GHG emissions of six biofuel pathways by LCA in (the) People's Republic of China. Appl Energ 2009; 86: S197-208.
[16] Maraver D, Rezeau A, Sebastian F, et al. In Thermodynamic optimization of a trigeneration system based on biomass combustion, 17th European Biomass Conference, Hamburg, 2009; pp. 1368-76.

[17] Sebastian F, Royo J, Gomez M. Cofiring versus biomassfired power plants: GHG (Greenhouse Gases) emissions savings comparison by means of LCA (Life Cycle Assessment) methodology. Energy 2011; 36: 2029-37. http://dx.doi.org/10.1016/j.energy.2010.06.003

[18] Basu P. Biomass gasification and pyrolysis: practical design and theory. Academic press 2010.

[19] Hwang CL, Yoon K. Multiple attribute decision making. Berlin \& New York: Springer-Verlag 1981. http://dx.doi.org/10.1007/978-3-642-48318-9

[20] Saaty TL, Peniwati K. Group decision making: drawing out and reconciling differences 2013.

[21] Zhang Y, Zhou S, Shu F. Fuzzy mathematics method and its application[M]. Beijing: Coal Industry Press 1992.

[22] Xiao B, Zhou YB, Li JF. Circular economy technologies of biomass energy. Beijing: Chemical Industry Press 2006.

[23] Lei ZM. Technical and economic synthetic evaluation. Beijing: China Standards Press 2004.

[24] Warnecke R. Gasification of biomass: comparison of fixed bed and fluidized bed gasifier. Biomass Bioenergy 2000; 18: 489-97. http://dx.doi.org/10.1016/S0961-9534(00)00009-X

[25] Wu CZ, Ma LL. Current status of biomass gasification power generation technologies in China. Sci Technol Industry China 2006; 2006: 76-9.

[26] Zhu XF, Zheng JL. Development of biomass pyrolysis device and its experimental research. Eng Sci 2006; 8: 89-93.

[27] Chen BM, Chen AN, Zhang ZF, Du HL. Analysis on the driving and constraint factors of crop straw gasification and commercialization development. J Nat Resour 2007; 22: 628.

[28] Chen WP, Chen YW, Liu ZF. The application and development of the biomass gasification industrial process technology. J Henan University (Nat Sci) 2007; 37: 35-41.

[29] Chen YS,Cao GQ, Zhang ZY, Zhu DW. Technical and economic evaluation for village-level straw Gasification System for central gas supply. Agri Dev Equip 2007; 6: 11-5.

[30] Liu SC, Jiang JC. Conversion technology and utilization of biomass energy(II)-technology and equipment of biomass shaped fuel production. Biomass Chem Eng 2007; 41: 59-63.

[31] EFYP, Twelfth Five-Year Planning. In China, N. D. a. R. C. o., Ed. Beijing 2011.

[32] Sun C, Liang W. Status of bio-diesel development and production in China. Sino-Global Energy 2008; 13: 23-8.

[33] Yin FS, Zheng YK. Status of bio-diesel industry in China. Detergent Cosmetics 2008; 31: 1-3.

[34] Liu F, Yan Z, Zhang L. The current situation and countermeasures proposals of rural biogas in Dalian. Mod Agric Sci 2008; 1: 19. 